\title{
Revestimentos de cobre em aço inoxidável 304L por laser cladding
}

\author{
M. Reis ${ }^{(*)}$, S. Estanislau $(*)$, A. Cabral ${ }^{(*)}$, P. Peças $^{(*)}$ e H. Gouveia ${ }^{(*)}$
}

Resumo: Foi estudada a aplicação de revestimentos de Cobre sobre aço inoxidável AISI 304L, pela técnica de Laser Cladding. Analisam-se alguns aspectos do processo, relacionando-os com a qualidade do revestimento. E também discutida a influência de vários parâmetros do processo como a velocidade de processamento e distância focal. Tendo-se obtido revestimentos de pista simples de Cobre com uma boa aparência, uma elevada aderência e um bom acabamento superficial, criou-se uma base de referência para estudos posteriores nomeadamente de aplicação multi-pista tendo em vista a aplicação industrial.

Palavras Chave: Laser cladding. Revestimentos de cobre.

\section{Copper coatings on stainless steel by laser cladding}

\begin{abstract}
Copper laser cladding was performed on AISI 304L stainless steel. Some process parameters like process speed and focal point were analysed and it was established its influence on the quality of the coating. Simple track coatings were achieved with good aspect, good adherence and good surface finishing. Therefore, a reference basis for further developments related to industrial application, was
\end{abstract} created.

Keywords: Laser cladding. Copper coatings.

\section{INTRODUÇÃO}

A vasta aplicabilidade do Laser, nos nossos dias resulta das suas grandes potencialidades relativamente ao processamento de materiais. Os processos para os quais se encontram mais direccionados são nomeadamente a soldadura, o corte, a marcação e os tratamentos superficiais, nos quais se inclui o revestimento de superfícies - Laser Cladding.

Esta técnica, tem como objectivo a fusão de um metal sobre a superfície de um substrato com a menor diluição possível (inferior a 10\%). Uma diluição igual a zero corresponderia a uma situação ideal equivalente à ausência de contaminação do revestimento. Por seu turno para situações em que a diluição da superfície solidificada é superior a $20 \%$ o processo designa-se por "Alloying". (1)

O material do revestimento apresenta-se na forma de um pó fino que é introduzido numa corrente de gás inerte e direccionado para a zona de

(1) ISQ - Instituto de Soldadura e Qualidade, Portugal. Estrada Nacional 249 - Km 3, Cabanas - Leião (TagusPark), Apartado 119, 2781 OEIRAS Codex. (Portugal). interacção entre o Laser e o substrato. (Figura 1). As partículas de pó aderem ao substrato formando o revestimento após a fusão deste, situação que apenas ocorre se a potência fornecida ao sistema for suficiente. Em condições de funcionamento optimizadas a radiação Laser será responsável pela fusão dos pós e do substrato.(2)

A extensão da diluição é controlada através do fluxo de pó fornecido ao processo. A optimização do fluxo de pó irá corresponder a uma diluição mínima e a uma deposição máxima, este parâmetro será também dependente da densidade de potência e

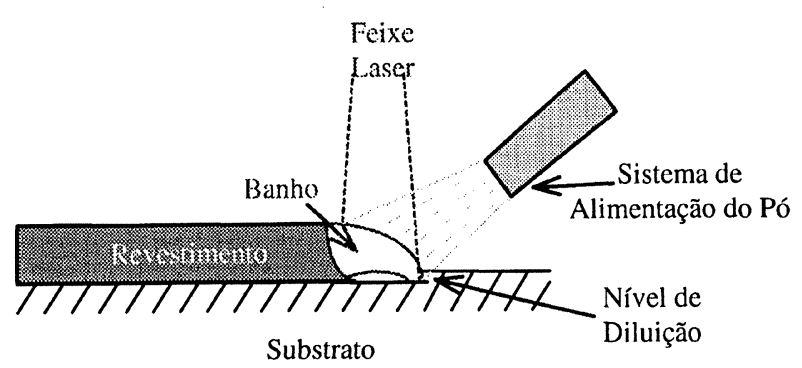

FIG. 1.- Laser cladding com injecção de pó. FIG. 1.-Laser cladding with blown powder. 
do modo do feixe laser. Fluxos de pó baixos originam um aumento da diluição e consequentemente uma diminuição da deposição de pó. Para fluxos de pó elevados o efeito é revertido até que, para um determinado fluxo a pista torna-se continua.

Relativamente ao ângulo de injecção de pó, o seu maior efeito recai na variação da velocidade de injecção de pó no banho de fusão. $\mathrm{O}$ injector deve ser posicionado por forma a que toda a zona de fusão seja preenchida com pó. Se a velocidade de injecção de pó for muito elevada, não haverá tempo para ocorrer fusão nas partículas do revestimento e consequentemente o revestimento será de baixa qualidade tendo em conta que as ligações pó substrato são de fraca intensidade.

O Cobre apresenta uma vasta gama de propriedades que justificam a sua utilização extensiva como material de revestimento. Destas propriedades destaca-se a elevada condutividade eléctrica.

\section{DESCRIÇÃO EXPERIMENTAL}

O material base utilizado (substrato a revestir) foi o aço inoxidável austenítico AISI 304L cuja composição química e propriedades mecânicas podem ser observadas na tabela I. A preparação das amostras foi realizada através da remoção das sujidades com acetona, visto que quaisquer impurezas na superfície da amostra irão interactuar com a radiação incidente provocando alteração da absorção de energia por parte dos materiais.

O material a pulverizar foi o pó AMDRY 3263, cujas características podem ser observadas na tabela II.

$\mathrm{Na}$ figura 2 e 3, ilustra-se o diagrama esquemático da montagem experimental utilizada e que a seguir se descreve (sistema completo e um pormenor da cabeça de cladding, respectivamente).

O sistema Laser utilizado foi um Rofin-Sinar

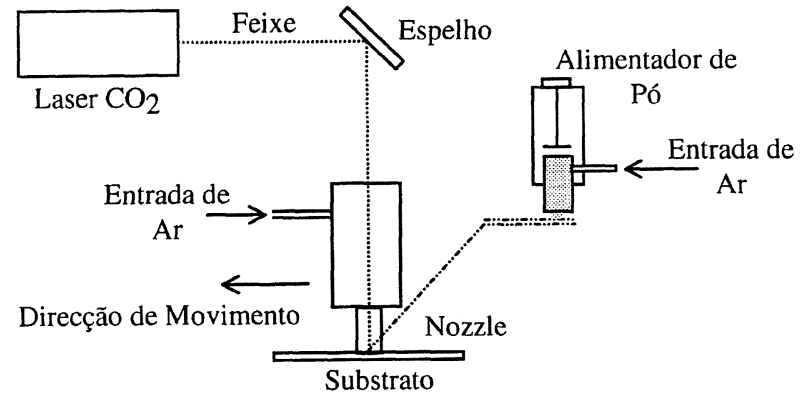

FIG. 2.- Representação esquemática da montagem experimental.

FIG. 2.- Schematic representation of the experimental setting.

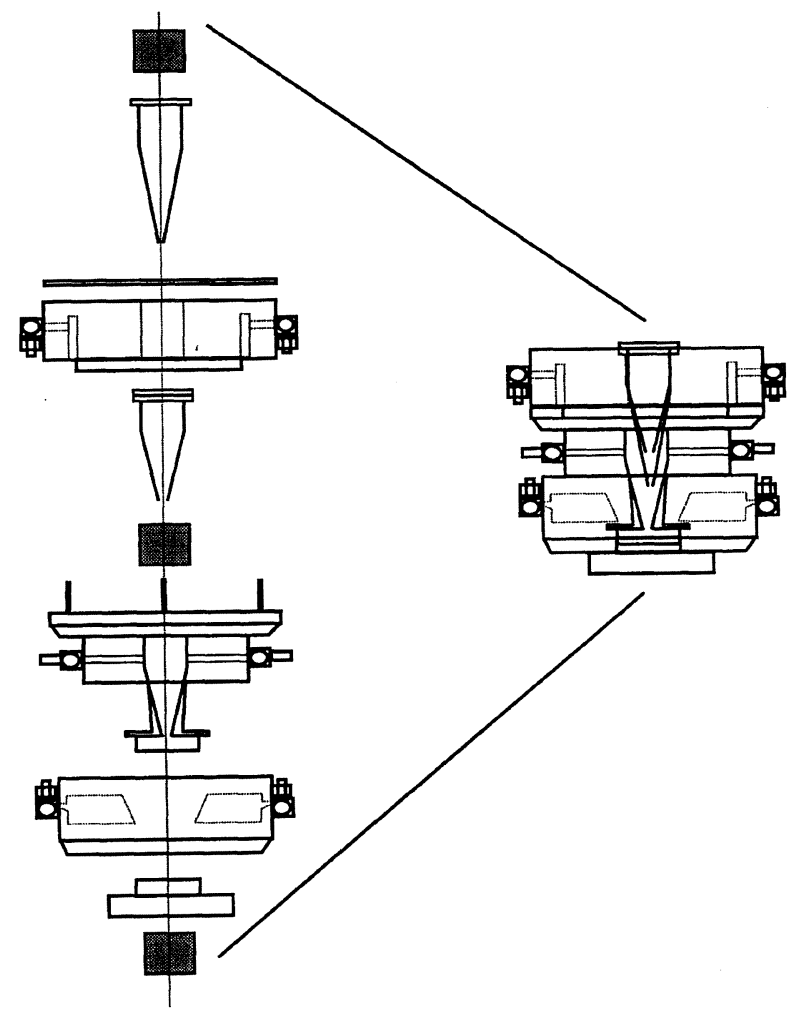

FIG. 3.- Cabeça de Laser Cladding.

FIG. 3.-Laser Cladding nozzle.

TABELA I.- Composição química (\%peso) e propriedades mecânicas da liga AISI 304L.

TABLE I.-Chemical composition (\% weight) and mechanical properties of AISI 304L.

\begin{tabular}{|l|c|c|c|cc|c|c|c|c|c|c|}
\hline Material & $\mathrm{C}$ & $\mathrm{Mn}$ & $\mathrm{Si}$ & $\mathrm{P}$ & $\mathrm{S}$ & $\mathrm{Cr}$ & $\mathrm{Ni}$ & Outros & $\begin{array}{c}\text { Dimensões } \\
(\mathrm{mm})\end{array}$ & $\begin{array}{c}\sigma \text { cedência } \\
\left(\mathrm{N} / \mathrm{mm}^{2}\right)\end{array}$ & $\begin{array}{c}\text { UTS } \\
\left(\mathrm{N} / \mathrm{mm}^{2}\right)\end{array}$ \\
\hline AISI 304L & 0,03 & 2,00 & 1,00 & 0,045 & 0,030 & $18,00-20,00$ & $8,00-12,00$ & - & $50 \times 80 \times 3$ & 170 & 485 \\
\hline
\end{tabular}

TABELA II.- Composição química e granulometria dos pós depositados nos ensaios de plasma.

TABLE II.- Chemical composition and ganule size of powders used in plasma experiments.

\begin{tabular}{|c|c|c|c|c|c|c|c|c|c|}
\hline \multirow{3}{*}{$\begin{array}{c}\text { Material } \\
\text { Depositado }\end{array}$} & \multirow{5}{*}{ Tipo } & \multicolumn{5}{|c|}{ Composição Química } & \multirow{2}{*}{$\begin{array}{c}\text { Ponto de } \\
\text { Fusão }\end{array}$} & \multirow{2}{*}{ Granulometría } \\
\cline { 2 - 8 } & $\mathrm{Cu}$ & $\mathrm{Al}$ & $\mathrm{Fe}+\mathrm{Si}$ & $\mathrm{Zn}$ & $\mathrm{Mg}$ & Outros & $1080^{\circ} \mathrm{C}$ & $-45+5 \mu \mathrm{m}$ \\
\hline
\end{tabular}


RS600 de 6 kW de potência, a operar em contínuo. Para cada valor de potência a ser utilizada, a respectiva densidade de potência é controlada através de um ajuste do diâmetro do feixe no ponto de interacção com o material a tratar, factor este que se controla através da variação da distância focal do sistema óptico. Relativamente à alimentação de pó, esta é feita com recurso a um sistema de injecção de pó Plasma-Technik, que debita uma quantidade de pó proporcional à rotação imprimida ao seu prato giratório. $\mathrm{O}$ pó é fornecido através de uma corrente gasosa e depositado num dos cones da cabeça de cladding que o distribui pelo feixe de Laser. A combinação correcta da velocidade do disco e do fluxo de gás asseguram o fornecimento adequado do pó ao Laser. Para a alimentação de pó se dar de forma mais homogénea, utiliza-se Argon com uma pressão de 1.5 bar e um caudal de 41/min para a injecção de pó. Para assegurar a ausência de oxidação nas pistas a depositar, é utilizado um gás de protecção coaxial (Argon) com um caudal da ordem dos $15 \mathrm{l} / \mathrm{min}$.

Na tabela III podem observar-se as condições de ensaio utilizadas no decurso deste trabalho de investigação.

As amostras revestidas por Laser Cladding são classificadas em dois grupos correspondentes a duas distâncias de focagem ( 30 e $35 \mathrm{~mm}$ abaixo do ponto focal) como se pode observar nas tabelas IV e V.

A analise laboratorial executada consistiu nos seguintes ensaios:

- Caracterização microestrutural das secções transversais das pistas (microscópio óptico);

- Medidas das dimensões das pistas (microscópio óptico);

- Ensaios de rugosidade sobre a superfície revestida (rugosímetro Mahr Perthen modelo S6P);

- Ensaios de dureza vickers nas secções transversais das pistas com uma carga de $200 \mathrm{~g}$ a actuar durante $15 \mathrm{~s}$ (microdurómetro Shimadzu modelo HSV-20);

Tabela III.- Condições de teste utilizadas no decorrer dos testes.

TABLE III.- Experimental test conditions.

\begin{tabular}{|l|l|}
\hline Sistema Laser & 2500 RF, 2.5 KW C.W. laser de CO2 \\
\hline Modo do feixe & Simetria circular, TEM 20 \\
\hline Distância Focal da Lente & $127 \mathrm{~mm}$ \\
\hline Gás de protecção & Argon, Fluxo de 151/min \\
\hline Material base & AISI 304L, espessura 3 mm \\
\hline Alimentado de pó & $\begin{array}{c}\text { PZ Twin-10C, gás utilizado: Argon a } \\
4 \text { 1/min, 1.5 bar }\end{array}$ \\
\hline Mesa & ESAB XY, ópticas flutuantes \\
\hline Posição de cladding & Pistas simples, arrefecimento ao ar \\
\hline
\end{tabular}

- Medidas de diluição pelo método das áreas (figura 4) nas secções transversais das amostras polidas e contrastadas;

- Ensaios de determinação das tensões residuais nas secções transversais (difractómetro de raios-X Rigaku Strainflex).

\section{RESULTADOS E DISCUSSÃO}

\subsection{Macro e Microestrutural}

Após observação de todas as pistas simples é possível destacar as seguintes.

- Amostra 2.2 que apresenta um revestimento bastante uniforme apesar da reduzida espessura figuras 5 e 7 ;

- Amostra 2.5 que apresenta, apesar de não uniforme, uma boa forma e uma zona de revestimento figura 6 .

Observa-se uma total ausência de porosidade no revestimento ocorrendo, no entanto, a formação de fissuras na direcção perpendicular à velocidade de processamento. $\mathrm{O}$ aparecimento destas fissuras está associado a uma das características da utilização do feixe Laser como fonte de calor que é a localização numa área reduzida da entrega de calor. $\mathrm{O}$ aquecimento localizado causa um arrefecimento muito rápido assim como um gradiente de temperaturas acentuado que causam frequentemente fissuração na solidificação.

Ambas as pistas seleccionadas foram realizadas a uma distância de $35 \mathrm{~mm}$ abaixo do ponto focal. $\mathrm{Na}$ realidade, como se confirma nos resultados posteriores, esta desfocalização permitiu alcançar valores de diluição em média mais reduzidos, pistas com aspecto mais uniforme e espessuras de revestimento superiores. Estes resultados podem ser explicados devido ao facto de a zona de interacção feixe laser/material ser superior originando um menor fornecimento de energia por área (densidade de energia).
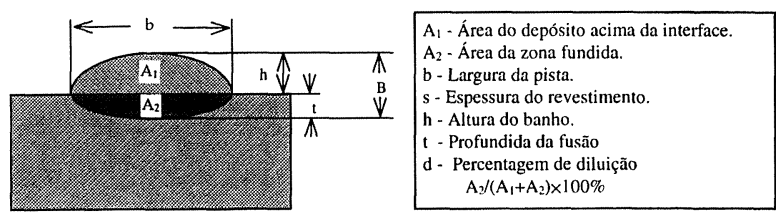

FIG. 4.- Cálculo da percentagem de diluição presente nos revestimentos por Laser.

FIG. 4.- Calculation of dilution present on the laser coatings. 


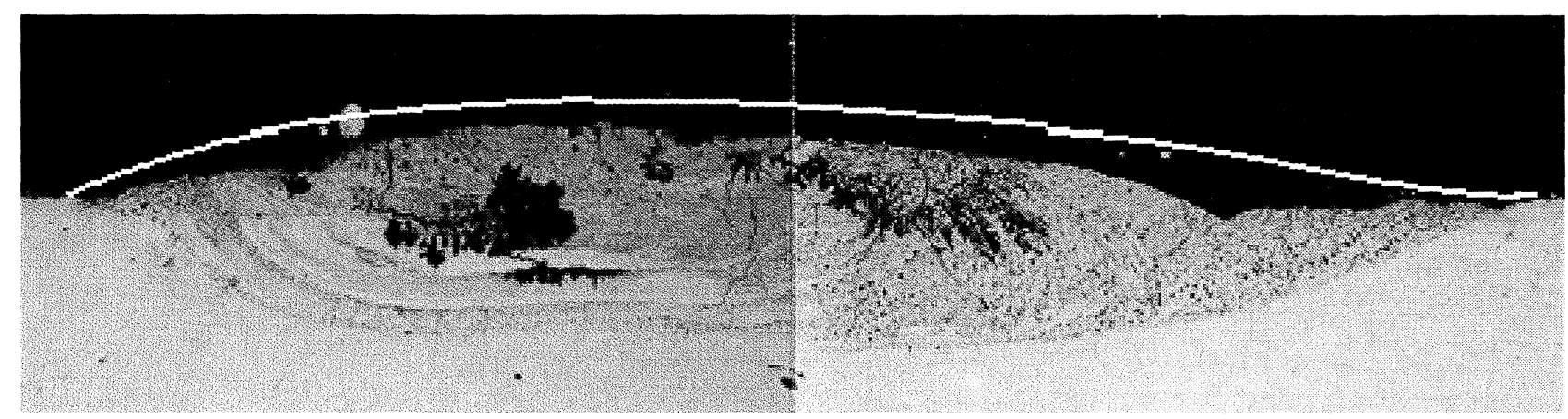

FIG. 5.- Secção transversal da pista $2.2(50 \times)$.

FIG. 5.- Cross section of the track $2.2(\times 50)$.

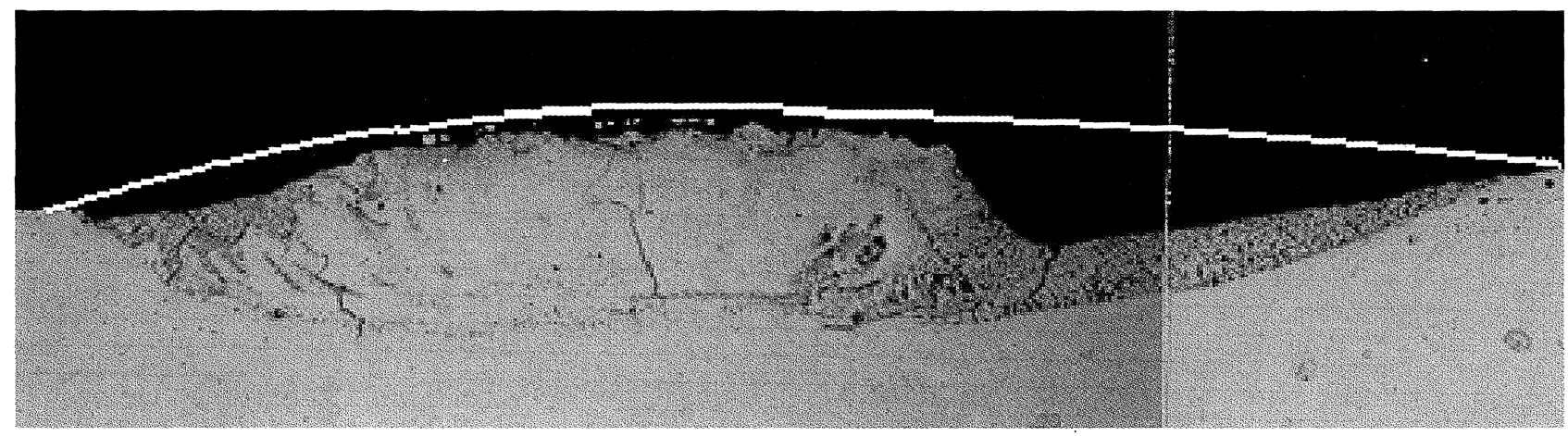

FIG. 6.- Secção transversal da Pista 2.5 (50×).

FIG. 6.-Cross section of the track $2.5(\times 50)$.

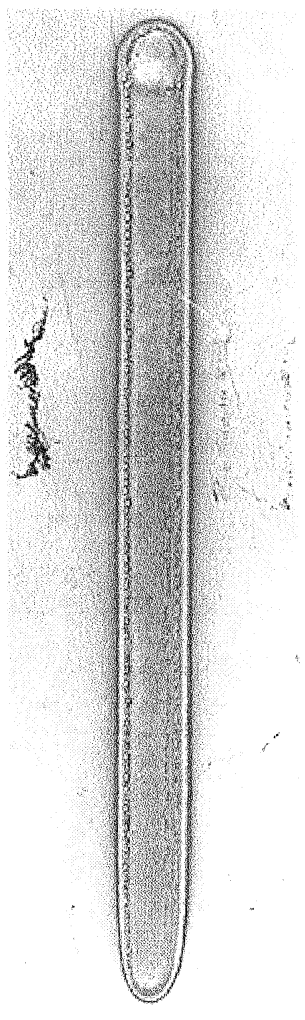

FIG. 7.- Pista 2.2.

FIG. 7.- Aspect of Track 2.2.
$\mathrm{Na}$ figura 8 pode observar-se a microestrutura da zona de diluição assim como da zona termicamente afectada. Em ambas as zonas verifica-se uma estrutura dendrítica, sendo a primeira mais fina devido a uma velocidade de arrefecimento mais elevada.

\subsection{Diluição}

Os resultados dos ensaios de diluição e de medida do perfil das pistas podem ser observados nas tabelas IV e V.

A sua observação para uma distância de $35 \mathrm{~mm}$ abaixo do ponto focal, permitiu relacionar a amostra com menor diluição com uma velocidade de $500 \mathrm{~mm} / \mathrm{min}$ (pista 2.5). Pela análise da figura 9 pode observar-se a sensibilidade da diluição do revestimento à flutuação da velocidade de processamento. $\mathrm{O}$ aumento de diluição corresponde no caso de velocidades superiores a $500 \mathrm{~mm} / \mathrm{min}$ a uma insuficiência de deposição de pó e no caso de velocidades inferiores a entregas térmicas excessivas. Esta situação reflecte o efeito conjunto dos parâmetros na qualidade do revestimento e coaduna-se perfeitamente com os fundamentos teóricos que nos dizem que, para velocidades de processamento menores, o tempo de interacção do 


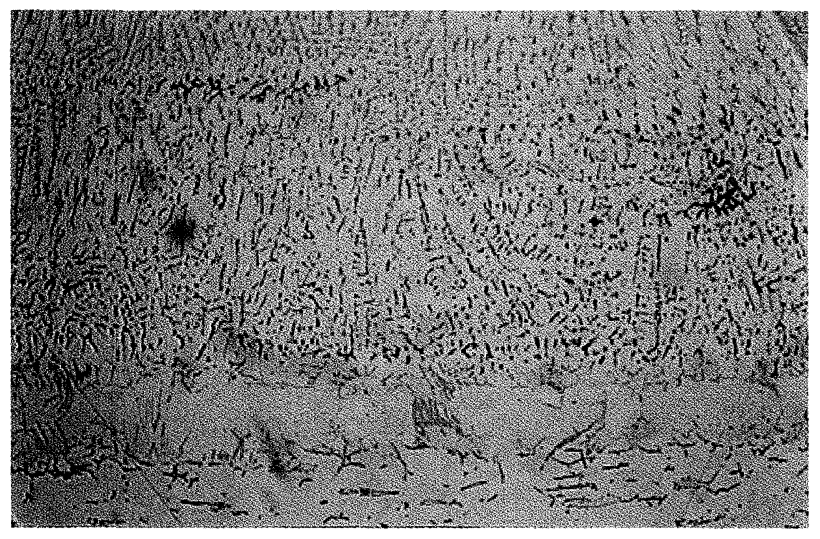

FIG. 8.- Microestrutura da zona de diluição de uma pista $(500 \times)$.

FIG. 8.-Dilution zone Microstructure of a Laser Cladding track $(\times 500)$.

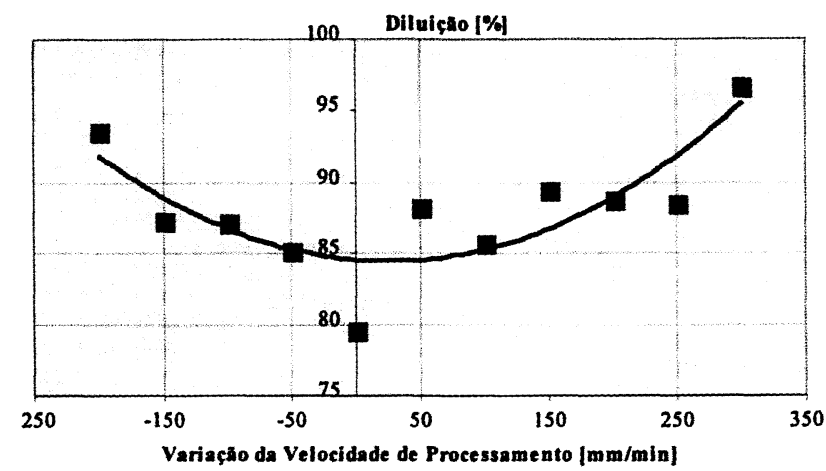

FIG. 9.- Variação da Velocidade de Prrocessamento vs Diluição para uma Distância de $35 \mathrm{~mm}$ Abaixo do Ponto Focal.

FIG. 9.- Process Speed Variation vs Dilution for a distance below the focal point of $35 \mathrm{~mm}$.

TABELA IV.- Resultados das amostras revestidas (Grupo 1).

TABLE IV.-Rerults of the coated' samples (Group 1).

\begin{tabular}{|c|c|c|c|c|c|c|}
\hline Amostra & $\begin{array}{c}\text { Potência } \\
{[\mathrm{W}]}\end{array}$ & $\begin{array}{c}\text { Velocidade } \\
{[\mathrm{mm} / / \mathrm{min}]}\end{array}$ & $\begin{array}{c}\text { Caudal de Pó } \\
{[\% \mathrm{rpm}]}\end{array}$ & $\begin{array}{c}\text { Largura da Pista } \\
{[\mu \mathrm{m}]}\end{array}$ & $\begin{array}{c}\text { Profundidade da Zona } \\
\text { Fundida }[\mu \mathrm{m}]\end{array}$ & $\begin{array}{c}\text { Diluição } \\
{[\%]}\end{array}$ \\
\hline 1.1 & 2.000 & 300 & 10 & 2.820 & 360 & 90,2 \\
1.2 & 2.000 & 350 & 10 & 2.780 & 320 & 93,6 \\
1.3 & 2.000 & 400 & 10 & 2.220 & 300 & - \\
1.4 & 2.000 & 450 & 10 & 2.120 & 300 & 93,8 \\
1.5 & 2.000 & 500 & 10 & 2.000 & 340 & 97,4 \\
1.6 & 2.000 & 550 & 10 & 2.040 & 280 & 91,0 \\
1.7 & 2.000 & 600 & 10 & 2.930 & 220 & 87,2 \\
1.8 & 2.000 & 650 & 10 & 2.940 & 220 & 91,3 \\
1.9 & 2.000 & 700 & 10 & 2.920 & 220 & 92,2 \\
\hline
\end{tabular}

TABELA V.- Resultados das amostras revestidas (Grupo 2).

TABLE V.- Results of the coated samples (Group 2).

\begin{tabular}{|c|c|c|c|c|c|c|}
\hline Amostra & $\begin{array}{c}\text { Potência } \\
{[\mathrm{W}]}\end{array}$ & $\begin{array}{c}\text { Velocidade } \\
{[\mathrm{mm} / / \mathrm{min}]}\end{array}$ & $\begin{array}{c}\text { Caudal de Pó } \\
{[\% \mathrm{rpm}]}\end{array}$ & $\begin{array}{c}\text { Largura da Pista } \\
{[\mu \mathrm{m}]}\end{array}$ & $\begin{array}{c}\text { Profundidade da Zona } \\
\text { Fundida }[\mu \mathrm{m}]\end{array}$ & $\begin{array}{c}\text { Diluição } \\
{[\%]}\end{array}$ \\
\hline 2.1 & 2.000 & 300 & 10 & 2.760 & 520 & 93,6 \\
2.2 & 2.000 & 350 & 10 & 2.660 & 500 & 87,3 \\
2.3 & 2.000 & 400 & 10 & 2.560 & 460 & 87,1 \\
2.4 & 2.000 & 450 & 10 & 2.360 & 400 & 85,2 \\
2.5 & 2.000 & 500 & 10 & 2.340 & 240 & 79,6 \\
2.6 & 2.000 & 550 & 10 & 2.180 & 340 & 88,3 \\
2.7 & 2.000 & 600 & 10 & 2.060 & 300 & 85,7 \\
2.8 & 2.000 & 650 & 10 & 2.160 & 300 & 89,4 \\
2.9 & 2.000 & 700 & 10 & 1.880 & 260 & 88,8 \\
3.0 & 2.000 & 750 & 10 & 1.820 & 280 & 88,5 \\
3.1 & 2.000 & 800 & 10 & 1.760 & 220 & 96,6 \\
\hline
\end{tabular}


feixe laser com o material vai ser maior e como tal, o material será mais afectado.

A pista com menor diluição apresentou um valor de $79.6 \%$, valor que se encontra muito acima do resultado pretendido (10\%). Este facto deve-se a um fornecimento de energia exagerado para as velocidades utilizadas no processo, no entanto, permite concluir que a aderência do revestimento foi na realidade efectiva.

\subsection{Dimensões das Pistas}

As medidas das dimensões das pistas permitiram relacionar o seu perfil com a velocidade de processamento utilizada.

Ambas as medidas do perfil das pistas mostraram uma forte dependência da velocidade de processamento, conforme mostram as figuras $10 \mathrm{e}$ 11. Como era de esperar observa-se um aumento da largura da pista e uma diminuição da profundidade com o aumento da velocidade. No que se refere à comparação entre as duas distâncias abaixo do ponto focal, os maiores valores observados para os $35 \mathrm{~mm}$ podem ser justificados pela zona fundida incluir o revestimento. Isto é, para uma distância de $35 \mathrm{~mm}$ abaixo do ponto focal embora a zona de

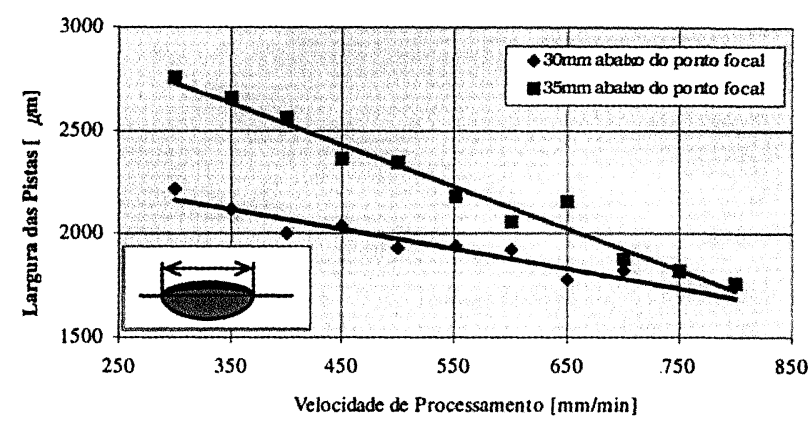

FIG. 10.- Velocidade de Processamento vs Largura das Pistas.

FIG. 10._- Process Speed vs Width of the tracks.

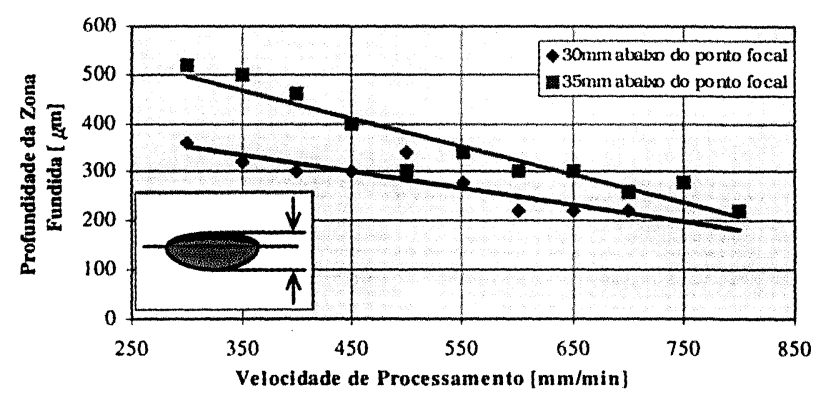

FIG. 11.- Velocidade de Processamento vs Profundidade da Zona Fundida.

FIG.11.- Process Speed vs Depth of the melted zone. diluição seja inferior a espessura do revestimento é em média superior.

A avaliação da espessura das pistas não foi quantitativa devido à não homogeneidade das mesmas, mas foi possível eleger a pista 2.5 (2000 $\mathrm{KW} ; 500 \mathrm{~mm} / \mathrm{min} ; 35 \mathrm{~mm}$ abaixo do ponto focal) como aquela com um valor superior. Por seu torno a pista $2.2(200 \mathrm{KW} ; 350 \mathrm{~mm} / \mathrm{min} ; 35 \mathrm{~mm}$ abaixo do ponto focal) mostrou apesar de reduzida uma espessura mais homogénea.

\subsection{Rugosidade}

Os ensaios de rugosidade realizados permitiram obter os valores de Ra (média aritmética de todas as áreas do perfil de rugosidade). Observa-se sempre uma superfície do revestimento rugosa, com partículas de cobre não fundidas e distribuição não homogénea de pó, situação que influência os valores de rugosidade obtidos. Na realidade um aumento da velocidade de processamento conduz a uma menor quantidade de partículas não fundidas assim como a uma diminuição da rugosidade média (Ra). Esta relação pode ser observada no gráfico 12. O mesmo gráfico permite verificar que as pistas efectuadas a $35 \mathrm{~mm}$ abaixo do ponto focal apresentam uma rugosidade média inferior às pistas com as mesmas velocidades mas efectuadas a $30 \mathrm{~mm}$ abaixo do ponto focal. Esta consideração apoia a afirmação de que este desfocamento será favorável.

\subsection{Microdureza}

Os ensaios de microdureza foram efectuados com uma carga de $200 \mathrm{~g}$ a actuar durante $15 \mathrm{~s}$ (Tabela VI).

Interessa referir que o aço inoxidável utilizado nos testes apresenta uma dureza de aproximadamente $160 \mathrm{HV}$ sem qualquer tratamento por Laser. Por seu turno o revestimento de Cobre apresentou durezas de $114 \mathrm{HV}$.

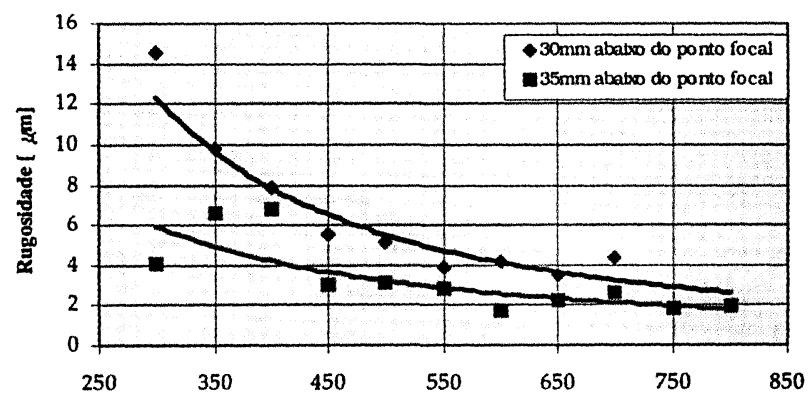

FIG. 12.- Velocidade de Processamento vs Rugosidade. FIG. 12.-Process Speed vs Roughness. 
TABELA VI.- Medição das microdurezas nas amostras mais exemplificativas do terceiro grupo de ensaios. Dureza Vickers [HV0.2].

TABLE VI.- Microhardeness measurements of the most representative samples in the third group of experiments.

\begin{tabular}{|c|c|c|c|c|c|c|c|c|c|}
\hline & \multicolumn{10}{|c|}{ Dureza Vickers [HV0,2] } \\
\cline { 2 - 11 } Amostra & $50 \mu \mathrm{m}$ & $100 \mu \mathrm{m}$ & $200 \mu \mathrm{m}$ & $400 \mu \mathrm{m}$ & $600 \mu \mathrm{m}$ & $800 \mu \mathrm{m}$ & $1.000 \mu \mathrm{m}$ & $2.600 \mu \mathrm{m}$ & $2.800 \mu \mathrm{m}$ \\
\hline 2.2 & 102 & 100 & 119 & 139 & 198 & 200 & 190 & 203 & 187 \\
\hline 2.5 & 136 & 161 & 190 & 200 & 205 & 190 & 193 & 178 & \\
\hline
\end{tabular}

TABELA VII.- Resultados das tensões residuais para as amostras mais representativas do terceiro grupo de ensaios.

TABLE VII.-Residual tensile of the most representative samples in the third group of experiments.

\begin{tabular}{|c|c|c|c|}
\hline \multirow{2}{*}{ Amostra } & \multicolumn{3}{|c|}{ Tensões Residuais [Mpa] } \\
\cline { 2 - 4 } & Medida Exterior & Medida Interior & Medida Exterior \\
\hline Aço Inoxidável (Superficie) & \multicolumn{3}{|c|}{$-76 \pm 6$} \\
\hline Aço Inoxidável (Secção Transversal) & & $-247 \pm 42$ \\
\hline 1.7 & $-125 \pm 1$ & $40 \pm 4$ & $86 \pm 8$ \\
\hline 1.4 & - & $10 \pm 7$ & $47 \pm 8$ \\
\hline 1.5 & $16 \pm 2$ & $-43 \pm 6$ & $-113 \pm 15$ \\
\hline 1.7 & $-93 \pm 5$ & $38 \pm 8$ & $58 \pm 16$ \\
\hline 1.8 & $116 \pm 11$ & $92 \pm 3$ & $41 \pm 13$ \\
\hline
\end{tabular}

Por observação dos valores obtidos verificamos que, no geral as amostras diminuíram a dureza na zona de diluição $(50$ e $100 \mu \mathrm{m})$ relativamente ao material base. Este facto é esperado uma vez que na zona de diluição existe uma inserção de cobre, elemento mais ductil. No que se refere ao material base este sofreu um a grande entrega térmica que conduziu a um aumento de dureza por recristalização do aço inoxidável. A área afectada pela calor chegou a atingir o extremo oposto da chapa revestida, situação a minimizar em futuros ensaios.

\subsection{Tensões Residuais}

Em todos os processos que utilizam radiação laser podem surgir problemas pela formação de tensões residuais. Estas podem causar distorção ou mesmo fissuração, situações a evitar. Deste modo é importante ter em conta a influência do procedimento nas tensões residuais. A sua origem recai num arrefecimento não uniforme conjuntamente com qualquer transformação de estado que possa ocorrer.

As medidas das tensões residuais foram realizadas na secção transversal da amostra sempre à mesma distância da superfície revestida. Os resultados mostram que são induzidas tensões residuais de tracção na superfície revestida do substrato. Este facto resulta na inserção de fissuras no revestimento e na zona de diluição assim como na deformação da chapa, situação a evitar. Deste modo em futuros trabalhos torna-se imperativo um controlo cuidado das tensões residuais.

\section{CONCLUSÕES}

Os resultados obtidos para os revestimentos realizados por laser permitiram uma análise geral da influência dos diferentes parâmetros nas características dos revestimentos e conduziram a revestimentos com um bom aspecto, uma elevada aderência e um bom acabamento superficial. As características anteriores foram acompanhadas de níveis de diluição muito elevados cujo melhoramento se impõe. Podemos concluir que os revestimentos por laser apresentam-se como promissores para o revestimento de peças de reduzidas dimensões - trabalhos de precisão.

\section{REFERENCIAS}

(1) "Laser Materials Processing", LU/TWI Laser Materials Processing Course, 29 April - 1 May 1997.

(2) Weerasinghe, V.M., Steen, W.M. "Laser Cladding with Pneumatic Powder Delivery", Applied Laser Tooling, 1987. 
(3) Crafer, R.C., Oakley, P.J. "Process and Physical Aspects of Continuos Wave Laser Processing", Applied Laser Tooling, 1987.

(4) Honeycombe, R.W.K. "Aços - Microestrutura e Propriedades", Fundação Calouste Gulbenkian, 1982.

(5) Brooks C. R. "Heat Treatment Struture and Properties of Nonferrous Alloys", American Society for Metals, 1982.

(6) "Melhoramento das Características Eléctricas e Magnéticas Superficiais do Aço Inoxidável, por Revestimento por Laser e por Plasma", Projecto CERN/P/FAE/1041/95.

(7) Peças P., Rodrigues S. "Laser Cladding for Thin Copper Layer on 316L Stainless Steel", Instituto de soldadura e Qualidade, Lisboa, 1975.

(8) Pelletier J.M. "Surface Modifications of Materials: New Technologies", Comett 8709 Ca, France, 1995.
(9) Crafer, R.C., Oakley P.J. "Laser Processing in Manufacturing", Chapman \&Hall, London, 1993.

(10) "5th European Conference on Laser Treatment of Materials", ECLAT'94, 1994.

(11) CotTrell A.H. "Introdução à Metalurgia", (Tradução M.A. Fortes, J.P. Botas), Fundação Calouste Gulbenkian, Lisboa, 1975.

(12) Sмiтh W.F. "Principles of Materials Science and Engineering", $2^{\text {nd }}$ Edition, McGraw-Hill International Editions, 1990.

(13) Stevens R.H. "Atlas of Microstructures of Industrial Alloys", Metals Handbook, $8^{\text {th }}$ Edition, Vol. 7, , ASM 1979.

(14) "Produção de revestimentos de Alumínio em aços inoxidáveis e Nb" Projecto CERN/P/CA/135/94. 